\title{
Proceedings of the Sixth International Conference on
}

Asian and Pacific Coasts (APAC 2011)

December 14 - 16, 2011, Hong Kong, China

\section{INTERACTION BETWEEN HYDRODYNAMICS AND SALT MARSH DYNAMICS: AN EXAMPLE FROM JIANGSU COAST}

\author{
Z. HU, M.J.F. STIVE, T.J.ZITMAN \\ Department of Hydraulic Engineering, Delft University of Technology, Stevinweg 1 \\ Delft, $2628 C N$, the Netherlands \\ Q.H. YE, Z.B.WANG, A. LUIJENDIJK \\ Deltares, Rotterdamseweg 185 \\ Delft, 2629 HD, the Netherlands \\ Z. GONG \\ State Key Laboratory of Hydrology-Water Resources and Hydraulic Engineering, Hohai University, \\ Xikang road 1, Nanjing, 210098, China \\ T. SUZUKI \\ Ghent University / Flanders Hydraulics Research, Berchemlei 115 \\ Antwerp, B-2140, Belgium
}

\begin{abstract}
Salt marshes are distributed along more than $400 \mathrm{~km}$ of the Jiangsu coast in Eastern China, which are regarded as important habitats and serve as coastal protection as well. Previous research has proven that salt-marsh vegetation can reduce current velocity and dampen waves by its stems and leaves. Reversely, hydrodynamic forces also have a significant influence on the growth of salt-marsh vegetation. To study the interaction between hydrodynamics and salt-marsh development on the Jiangsu coast, a 2D schematized model has been built by using a new interactive structure between flow, wave and vegetation modules of the process-based model Delft3D. In the hydrodynamic simulations, the impact of vegetation on waves and currents is quantified. In the vegetation growth module, the development of salt marshes is influenced by inundation time and shear stress from hydrodynamic simulations. The feedback loop is completed by hydrodynamic modules receiving the newly updated data of salt-marsh field from the vegetation growth module. The results show that wave height and current velocity are significantly influenced by vegetation. Reversely, the dynamics of marsh vegetation greatly rely on hydrodynamic conditions. Consequently, this interaction between hydrodynamics and salt marsh induces temporal variations of each other. In the model, the salt marsh is especially sensitive to the waves. Though wave height is relatively small on the Jiangsu coast, in terms of bed shear stress, waves may be of great importance to the development of salt marsh.
\end{abstract}




\section{Introduction}

In the eastern China, salt marshes cover about $410 \mathrm{~km}$ of the Jiangsu coast, with a maximum width of over $4 \mathrm{~km}$ [1]. Salt-marsh vegetation can reduce current velocity [2; 3] and wave energy through salt marsh canopy [4; 5]. Moreover, the vegetation-current feedback can strongly influence each other and the tidal landscape as well $[6 ; 7]$. To study the interaction between hydrodynamics and salt-marsh development on the Jiangsu coast, an integrated wave-flowvegetation model has been built. Specially, waves are included in the interaction model to count the impact of waves on the vegetation and vice versa.

Wanggang wetland in the middle part of the Jiangsu coast is picked as the study area, where salt marshes are widespread. Wanggang wetland is dominated by semi-diurnal tide. The tidal range is $3-4 \mathrm{~m}$ and the slope of tidal flat is about $0.55 \%$ [8]. The significant wave height over the intertidal flat is $0.1 \mathrm{~m}-0.2 \mathrm{~m}$ [9]. The dominant species of the salt-marsh vegetation is Spartina alterniflora [1], which is chosen as the representative vegetation in the model.

\section{Methods}

The interaction model has been built within the process-based Delft3D system in 2D [10]. Delft3D WAVE, FLOW and WAQ modules are employed to simulate wave-current-vegetation feedback pattern.

\subsection{Flow module}

In the flow module, marsh plants are schematized as rigid cylinders. The effect of vegetation on flow is counted as extra resistance in momentum equation [11]:

$$
M=-\frac{1}{2} \lambda u|u|
$$

Where $u$ is the current velocity $[\mathrm{m} / \mathrm{s}], \lambda$ is the resistance coefficient which is proportional to the product of stem density and diameter of plant cylinders, $\left[\mathrm{m}^{-1}\right]$.

\subsection{Wave module}

In the wave module, vegetation is also schematized as rigid vertical cylinders. Wave energy dissipation due to vegetation $\left\langle\varepsilon_{v}\right\rangle$ is given by [4]:

$$
\left\langle\varepsilon_{v}\right\rangle=\frac{1}{2 \sqrt{\pi}} \rho_{0} \tilde{C}_{D} b_{v} N\left(\frac{g k}{2 \sigma}\right)^{3} \frac{\sinh ^{3} k \alpha h+3 \sinh k \alpha h}{3 k \cosh ^{3} k h} H_{r m s}^{3}
$$

Where $\rho_{0}$ is the water density $\left[\mathrm{kg} \mathrm{m}^{-3}\right], h$ is the water depth $[\mathrm{m}],(a h)$ is the vegetation height $[\mathrm{m}], H_{r m s}$ is root mean square wave height [m], $k$ is wave number $\left[\mathrm{m}^{-1}\right], \sigma$ is angular frequency $\left[\mathrm{s}^{-1}\right], b_{v}$ is average diameter of plants $[\mathrm{m}]$, $N$ is the number of plants per square meter $\left[\mathrm{m}^{-2}\right], \tilde{c}_{D}$ is averaged drag coefficient $[-],\left\langle\varepsilon_{v}\right\rangle\left[\mathrm{N} \mathrm{m}^{-1} \mathrm{~s}^{-1}\right]$ is added in spectral action balance equation [12]. 


\subsection{Vegetation dynamic module}

The simulation of the vegetation module represents intrinsic growth and spatial spreading of vegetation [13]. It also counts mortality caused by inundation and shear stress [6]. Specially, as waves are included in the model, the bed shear stress is enhanced by wave-current interaction [14]. The mortality due to shear stress is assumed to be proportional to the maximum bed shear stress.

Vegetation height and stem diameter are assumed to be proportional to the stem density. After each time step, this module provides the newly updated space-depended vegetation height, diameter and density data for the next hydrodynamics simulations. As the dynamics of vegetation acts on longer time scale than hydrodynamics [15], the vegetation data is updated every 2 days.

\subsection{Model setting}

The flow domain covers an area of $8 \mathrm{~km}$ by $8 \mathrm{~km}$, which is set upon a constant slope from $4 \mathrm{~m}$ to $-12 \mathrm{~m}$ (as $0 \mathrm{~m}$ is the mean sea level). Tide is composed by $M 2$, $M 4$ and $S 2$, with amplitudes of $1.7 \mathrm{~m}, 0.2 \mathrm{~m}$ and $0.6 \mathrm{~m}$ respectively. The wave boundary is set $4 \mathrm{~km}$ further seaward than the flow boundary. As sheltered by offshore sand ridges in the southeast [8], waves are prescribed to come from northeast $\left(45^{\circ}\right)$. Locally generated waves by wind are neglected.

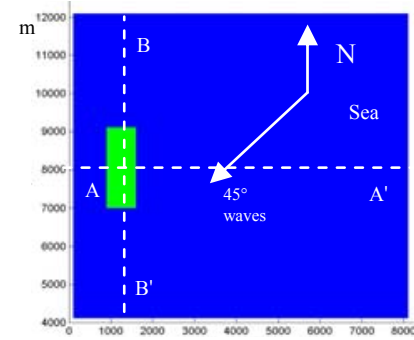

Figure 1a. Top view of the domain.

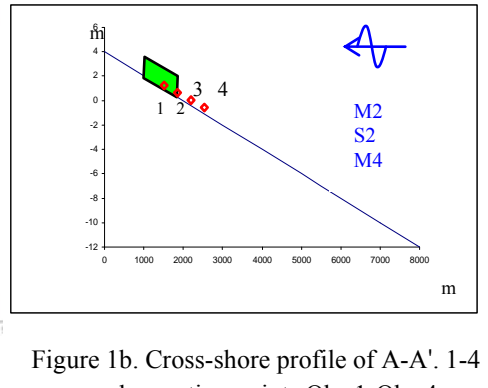

are observation points Obs.1-Obs.4

The initial vegetation patch is placed in the upper intertidal zone with an area of $700 \mathrm{~m}$ by $2000 \mathrm{~m}$ (Fig 1a). The simulation is carried out from May to October in the model, because it is the time that salt-marsh vegetation grows [16]. The base case is $\mathrm{C}_{\mathrm{V} 30}: 30$ meaning $30 \mathrm{~cm} H_{s}$ from boundary and " $V$ " meaning vegetation being taken into account in this case. Similarly, $\mathrm{C}_{\mathrm{N} 50}$ means that in this case $H_{s}$ from the boundary is $50 \mathrm{~cm}$ and there is no vegetation.

Cross sections $\mathrm{A}-\mathrm{A}^{\prime}$ and $\mathrm{B}^{-} \mathrm{B}^{\prime}$ represents cross-shore and long-shore directions respectively (Fig. 1a). A-A' is the mid-line of the tidal flat. There are 4 observation points (Obs.1 to Obs.4) on it. They are located at the mature marsh, fringe of the marsh, pioneer zone and bare tide flat respectively (Fig. 1b). 


\section{Results}

\subsection{Spatial variations of hydrodynamics}

Table 1. Spatial variations of $H_{s}$ and the magnitude e of current velocity $(|u|)$ along cross section A-A'

\begin{tabular}{|c|c|c|c|c|c|c|c|c|}
\hline & \multicolumn{4}{|c|}{$\begin{array}{l}\text { Mean significant wave height } H_{s} \\
(\mathrm{~cm}) \text { and [standard deviation] }(\mathrm{cm})\end{array}$} & \multicolumn{4}{|c|}{$\begin{array}{l}\text { Mean current velocity }|u|(\mathrm{cm} / \mathrm{s}) \\
\text { and [standard deviation] }(\mathrm{cm} / \mathrm{s})\end{array}$} \\
\hline Scenario & $\begin{array}{c}\text { Bare Tidal } \\
\text { flat }\end{array}$ & $\begin{array}{l}\text { Pioneer } \\
\text { zone }\end{array}$ & $\begin{array}{c}\text { Fringe of } \\
\text { marsh }\end{array}$ & $\begin{array}{l}\text { Mature } \\
\text { marsh }\end{array}$ & $\begin{array}{c}\text { Bare Tidal } \\
\text { flat }\end{array}$ & $\begin{array}{l}\text { Pioneer } \\
\text { zone }\end{array}$ & $\begin{array}{c}\text { Fringe of } \\
\text { marsh }\end{array}$ & $\begin{array}{l}\text { Mature } \\
\text { marsh }\end{array}$ \\
\hline $\mathrm{C}_{\mathrm{N} 30}$ & $9.4[0.8]$ & $7.8[1.2]$ & $6.0[2.3]$ & 3.7 [3.0] & $14.8[8.8]$ & 10.9 [5.6] & $10.3[5.8]$ & $7.3[7.2]$ \\
\hline $\mathrm{C}_{\mathrm{V} 30}$ & $8.3[0.6]$ & 6.8 [1.1] & $4.0[1.8]$ & $1.3[1.2]$ & $13.8[8.3]$ & $8.4[4.4]$ & $4.0[1.9]$ & $3.0[2.2]$ \\
\hline $\mathrm{C}_{\mathrm{N} 50}$ & 17.5 [1.3] & $14.3[2.2]$ & 10.9 [4.1] & $6.7[5.5]$ & $14.0[8.4]$ & $10.1[5.3]$ & 8.1 [4.1] & $5.6[3.6]$ \\
\hline $\mathrm{C}_{\mathrm{V} 50}$ & 16.5 [1.2] & $13.4[2.0]$ & 8.9 [3.5] & $2.1[2.0]$ & 13.2 [7.9] & $9.1[5.0]$ & $5.1[2.3]$ & $3.0[2.1]$ \\
\hline $\mathrm{C}_{\mathrm{N} 100}$ & 26.5 [1.9] & 21.4 [3.3] & $16.2[6.4]$ & $10.0[8.3]$ & 13.4 [8.0] & $9.7[5.0]$ & 7.7 [3.9] & 5.6 [3.4] \\
\hline $\mathrm{C}_{\mathrm{V} 100}$ & 23.4 [1.5] & $19.0[2.9]$ & $12.5[5.0]$ & $2.1[2.4]$ & $12.8[7.7]$ & $8.7[4.9]$ & 5.0 [2.2] & $3.0[2.1]$ \\
\hline
\end{tabular}

In the model, semi-diurnal tides with spring-neap tide cycle are well represented. The mean tide range is $3.5 \mathrm{~m}$. Flood currents run southward and ebb currents run northward (Fig. 2). The salt marsh is regularly flooded by high tides, which also delivers waves to the tidal flat (Fig. 3).

Results show that the presence of the salt marsh induces spatial variations of hydrodynamic forces. The significant wave height $\left(H_{s}\right)$ and the magnitude of current velocity $(|u|)$ are averaged over all the flooding times through half year. Remarkable reduction of both significant wave height and current velocity is shown in the cases with vegetation (Table 1).

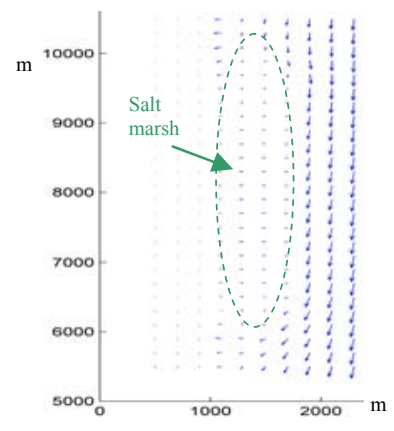

Figure 2. Flow velocity field during flood, $\mathrm{C}_{\mathrm{V} 30}$

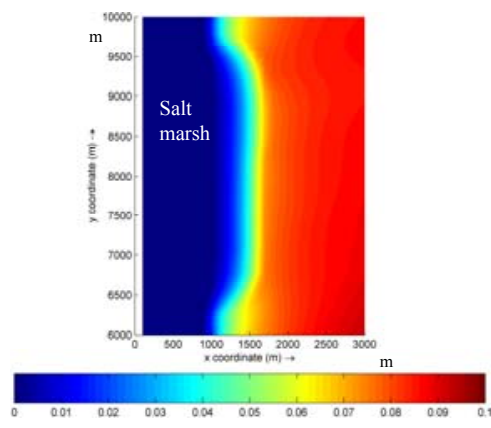

Figure $3 . H_{s}[\mathrm{~m}]$ distribution during flood, $\mathrm{C}_{\mathrm{V} 30}$

Salt marsh vegetation reduces wave energy efficiently. The salt marsh has a considerable impact on the spatial distribution of $H_{s}$ on the tidal flat (Fig. 3). In the base run with vegetation, the mean significant wave height decreases by 
$85 \%$ from bare tidal flat to the mature marsh, while the percentage of decrease is about $60 \%$ in the contrasting case without vegetation (Table 1).

Moreover, the efficiency of salt marsh dampening waves increases with incident wave height. In case $\mathrm{C}_{\mathrm{V} 100}$, the $H_{s}$ reduces by $90 \%$ through the vegetation field. However, the percentage of $H_{s}$ reduction remains around $60 \%$ for all the cases without marsh (Table 1.).

When the currents travel through the marsh canopy, the blockage effect of vegetation is significant (Fig. 2). During flood, the long-shore component of the mean current velocity along the B-B' is reduced from $15.7 \mathrm{~cm} / \mathrm{s}$ to $7.3 \mathrm{~cm} / \mathrm{s}$ at the northern edge of the marsh. At the southern edge, it restores from $4.8 \mathrm{~cm} / \mathrm{s}$ to $14.3 \mathrm{~cm} / \mathrm{s}$ (Fig. 2). Meanwhile, because of its small magnitude, the crossshore component only reduces slightly and it even increases around the northern and southern edges. In the cross-shore direction, vegetation also leads to higher reduction of time-averaged $|u|$ from seaward to landward (Table 1.)

\subsection{Salt marsh dynamics}
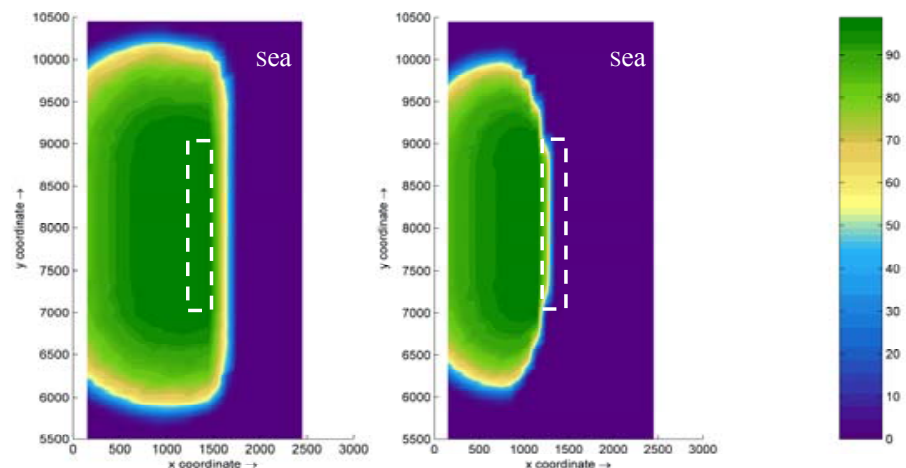

Figure 4. Salt marsh development after half year, the left one is $\mathrm{C}_{\mathrm{V} 30}$, the right one is $\mathrm{C}_{\mathrm{V} 300}$, the white dash line indicates the location of the initial marsh patch, and the legend indicates the stem density $\left[\mathrm{m}^{-2}\right]$

The development of the salt marsh is greatly influenced by the hydrodynamic force. Especially, the wave plays a crucial part in it. In the base run $\left(\mathrm{C}_{\mathrm{V} 30}\right)$, the salt marsh expands fast, which is similar to the reality of the Jiangsu coast [1] (Fig. 4). The mature salt marsh (stem density $\mathrm{N} \geq 60 \%$ max capacity) progresses $100 \mathrm{~m}$ seaward, with a $200 \mathrm{~m}$ pioneer zone in front of it. In the long-shore direction, the marsh expands $1000 \mathrm{~m}$ northward and $1200 \mathrm{~m}$ southward. By the end of October, the mean stem density of mature marsh increases from 50 to about $90 \mathrm{~m}^{-2}$. Mean height and diameter of S. alterniflora increases to $1.7 \mathrm{~m}$ and $0.95 \mathrm{~cm}$ respectively. These results are in agreement with references [1;17]. 
The marsh in the model is very sensitive to the incident waves. If timeaveraged $H_{s}$ increases to $16.5 \mathrm{~cm}$ on the bare tidal flat (Obs. 4), the marsh cannot expand seaward. When $H_{s}$ on the bare tidal flat increases to $30 \mathrm{~cm}$, the hydrodynamic forces become erosive to the initial marsh. With higher incident waves (e.g., $3 \mathrm{~m}$ ), the marsh will even retreat further to the landward (Fig. 4).

\subsection{Temporal variations of hydrodynamics}

As the marsh is active, $H_{s}$ and current velocity are also influenced by the dynamics of the marsh over time. This influence is significant especially on the fringe of the mature marsh and on the pioneer zone, where the interaction is more intense and distinct. The dynamics of marshes acts on a longer temporal scale than hydrodynamics [15]. To compare them, the results are averaged over every three spring-neap circles, approximately 45 days.
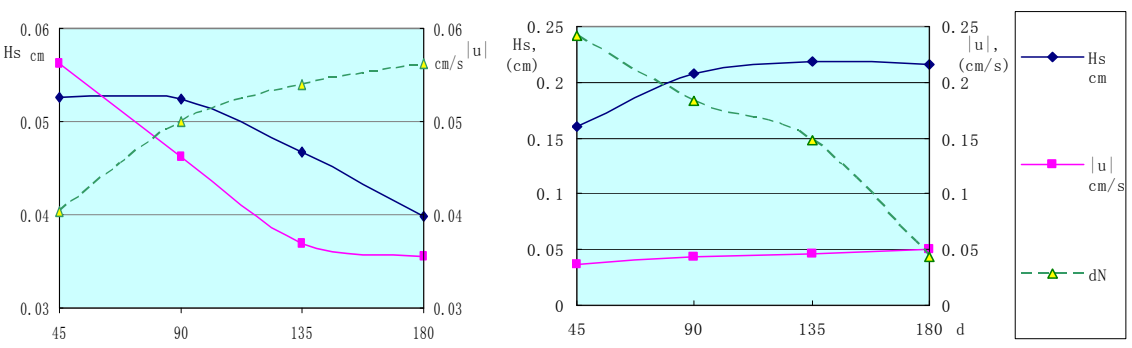

Figure 5. Temporal variation of hydrodynamics on the marsh fringe, the left one is from $\mathrm{C}_{\mathrm{V} 30}$, the right one is from $\mathrm{C}_{\mathrm{V} 120}$; the green dash lines $(\mathrm{dN})$ indicate the relative stem density of vegetation

Hydrodynamic forces can either decrease due to the marsh expansion or they could increase due to marsh retreat (Fig. 5). Whether the marsh will expand or retreat is determined by the strength of hydrodynamics. In the base run, the mean vegetation density increases by $40 \%$ on the fringe of marsh (Obs. 2), which leads to $25 \%$ and $40 \%$ decline of $H_{s}$ and $|u|$ respectively over half year. The decline of hydrodynamic forces leads to a more favorable environment for the salt marsh. In the $\mathrm{C}_{\mathrm{V} 120}$, hydrodynamic forces are erosive to the salt-marsh vegetation on the fringe. The marsh density decreases by $80 \%$, while $H_{s}$ and $|u|$ increases by $35 \%$ and $40 \%$ respectively (Fig. 5). In this case, hydrodynamic forces are amplified due to the degeneration of the salt marsh.

\subsection{Bed shear stress}

In the model, the mortality of S. alterniflora is assumed to be proportional to the max shear stress from current-wave interaction [14]. The critical shear stress is set at $0.26 \mathrm{~Pa}$ [18], beyond which some vegetation will be wiped out (Fig. 6). 
During high water level, shear stress due to currents alone is $0.02 \mathrm{~Pa}-0.10 \mathrm{~Pa}$ with a mean value of $0.045 \mathrm{~Pa}$ at the marsh fringe. As waves are included, the max bed shear stress from flow-wave interaction is $0.06 \mathrm{~Pa}-0.28 \mathrm{~Pa}$ in the base run on the fringe of marsh, with a mean value around $0.085 \mathrm{~Pa}$. Though waves are relatively small on the Jiangsu coast, field work shows that waves can enhance bed shear stress greatly [3;9]. Moreover, bed shear stress on the marsh due to waves alone is higher than that from currents along (Fig. 6). As incident wave height increases from $30 \mathrm{~cm}$ to $50 \mathrm{~cm}$, there is a higher chance that the vegetation on marsh fringe will be eroded.
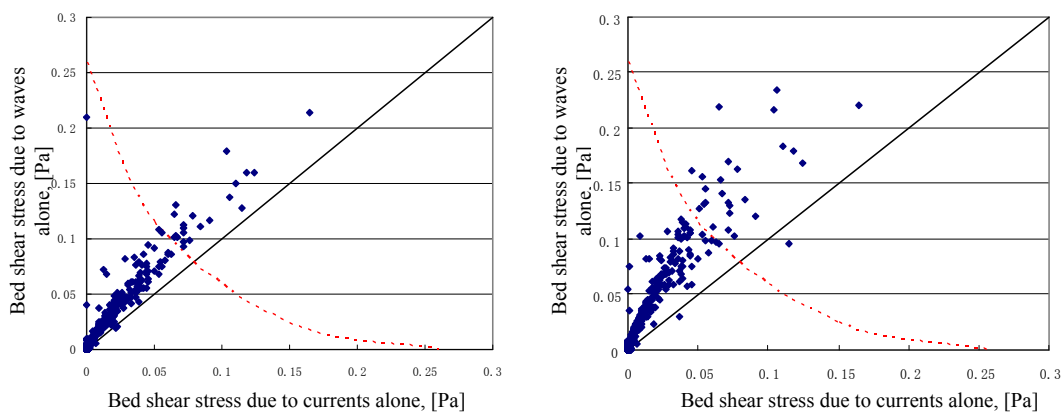

Figure 6. Comparison between bed shear stress induced by current alone and by wave alone at the fringe (Obs. 2) of the marsh. The left one is $\mathrm{C}_{\mathrm{V} 30}$, the right one is $\mathrm{C}_{\mathrm{V} 50}$, red dash lines indicate the critical shear stress $(0.26 \mathrm{~Pa})$ of plant mortality

\section{Discussion and Conclusion}

The results demonstrate a significant effect of vegetation on waves and currents. The base run $\left(\mathrm{C}_{\mathrm{V} 30}\right)$ successfully reproduces the rapid development of salt marshes on the Jiangsu coast $[1 ; 17]$. Furthermore, temporal variations of hydrodynamics due to the salt marsh development are evident (Fig. 5). Hence, it is necessary to employ dynamic marshes module other than static vegetation patches for fairly long-term hydrodynamic or morphodynamic prediction. The intertidal zone of the Jiangsu coast is very flat and the slope is very gentle [8]. Considering the homogeneous topography, the interaction between vegetation and hydrodynamics can be very important to the evolution of the landscape [6].

Wave height on the Wanggang tidal flat is small [8; 9], which may be one of the reasons that salt marshes are widespread there. Field measurements have indicated that in terms of bed shear stress waves may play a more important role in marsh dynamics than currents [3]. Model results show that bed shear stress is enhanced by waves, which leads to a higher mortality of S. alterniflora. Moreover, the shear stress due to waves alone is greater than that due to currents alone [3; 9]. It is the reason why the development of the marsh is sensitive to waves. Even a slight increase of $H_{s}(20 \mathrm{~cm})$ from the boundary will restrain the 
marsh from seaward propagation. With even higher waves, the marsh will retreat. This integrated model indicates that waves are important in the interaction between hydrodynamic and salt marsh development. The implementation of this model in the micro-topography and morphodynamics of salt marshes can be a future challenge.

\section{Acknowledgments}

The authors want to thank Drs. Mariëtte van Tilburg for her editorial support.

\section{References}

1. R.S. Zhang, Y.M. Shen, L.Y. Lu, S.G. Yan, Y.H. Wang, J.L. Li, Z.L. Zhang, "Formation of Spartina alterniflora salt marshes on the coast of Jiangsu Province, China". Ecological Engineering. 23, no. 295-105 (2004)

2. S. Temmerman, T. J. Bouma, G. Govers, Z. B. Wang, M. B. De Vries, P. M. J. Herman, "Impact of vegetation on flow routing and sedimentation patterns: Three-dimensional modeling for a tidal marsh". Journal of Geophysical Research F: Earth Surface. 110, no. 4 (2005)

3. D.P. Callaghan, T.J. Bouma, P. Klaassen, D. van der Wal, M.J.F. Stive, P.M.J. Herman, "Hydrodynamic forcing on salt-marsh development: Distinguishing the relative importance of waves and tidal flows". Estuarine, Coastal and Shelf Science. 89, no. 1 73-88 (2010)

4. F.J. Mendez and I.J. Losada, "An empirical model to estimate the propagation of random breaking and non-breaking waves over vegetation fields". Coastal Engineering. 51, no. 2 103-118 (2004).

5. Suzuki, T., "Wave dissipation over vegetation fields". Ph.D. thesis, Delft University of Technology (2011)

6. S. Temmerman, T.J. Bouma, J. Van de Koppel, D. Van der Wal, M.B. De Vries and P.M.J. Herman, "Vegetation Causes Channel Erosion in a Tidal Landscape". Geology. 35, no. 7, 631-634 (2007)

7. W. Vandenbruwaene, S. Temmerman, T. J. Bouma, P. C. Klaassen, M. B. de Vries, D. P. Callaghan, P. van Steeg, F. Dekker, L. A. van Duren, E. Martini, T. Balke, G. Biermans, J. Schoelynck, and P. Meire, "Flow interaction with dynamic vegetation patches: Implications for biogeomorphic evolution of a tidal landscape". Journal of Geophysical Research F: Earth Surface. 116, no. 1 (2011),

8. Ren M E, "Comprehensive Investigation of Coastal Zone and Tidal Land Resources of Jiangsu Province". Beijing: China Ocean Press. in Chinese (1986)

9. Y. Wang, S. Gao, and J. Jia, "High-resolution data collection for analysis of sediment dynamic processes associated with combined current-wave action over intertidal flats". Chinese Science Bulletin. 51, no. 7, 866-877 (2006).

10. G.R. Lessera, J.A. Roelvinka, J.A.T.M. van Kester, G.S. Stelling, "Development and validation of a three-dimensional morphological model". Coastal Engineering. 51, no. 8, 883-915 (2004).

11. Baptist, M. J., "Modelling flood plain biogeomorphology". Ph.D. thesis, Delft University of Technology. 274 (2005)

12. Booij, N., Ris, R.C., Holthuijsen, L.H., "A third-generation wave model for coastal regions 1. model description and validation". Journal of Geophysical Research. 104, 7649e7666 (1999)

13. Yodzis, P., "Introduction to theoretical ecology". New York, Harper \& Row, 384 p. (1989)

14. Fredsøe, J., "Turbulent boundary layer in wave-current interaction". Journal of Hydraulic Engineering. 110: 1103 (1984)

15. J.R.L. Allen, "Morphodynamics of Holocene salt marshes: A review sketch from the Atlantic and Southern North Sea coasts of Europe". Quaternary Science Reviews. 19, no. 12, 1155-1231 (2000).

16. Gallagher, John L., "Seasonal patterns in recoverable underground reserves in Spartina alterniflora Loisel". American Journal of Botany, (1983)

17. SHEN Yong-Ming, YANG Jing-Song, WANG Yan-Hong, FENG Nian-Hua, ZHOU Qin and ZENG Hua, "Impact of Sediment Supply on Spartina Salt Marshes Project supported by the National Natural Science Foundation of China". Pedosphere. 18, no. 5, 593-598 (2008)

18. Van Hulzen, J.B., Van Soelen, J., and Bouma, T.J., "Morphological variation and habitat modification are strongly correlated for the autogenic ecosystem engineer Spartina anglica (common cord grass)" Estuaries and Coasts. v. 30, p. 1-19. (2007) 